\title{
Agrupamento de empresas a partir de suas estratégias de precificação e níveis de desempenho: um estudo no setor metalmecânico de Caxias do Sul
}

\section{Companies' clustering from their pricing strategies and performance levels: a study in the metal-mechanic sector of Caxias do Sul}

\author{
EVANDRO BUSATA SACILOTO* \\ FABIANO LARENTIS** \\ GABRIEL SPERANDIO MILAN*** \\ DEONIR DE TONI ****
}

\section{RESUMO}

Este estudo verificou a constituição de grupos de empresas a partir de suas estratégias de precificação e níveis de desempenho. Como método de pesquisa, realizou-se uma pesquisa quantitativo-descritiva do tipo survey com os responsáveis pelo processo de precificação de 153 empresas afiliadas ao Sindicato das Indústrias Metalúrgicas e de Material Elétrico de Caxias do Sul (SIMECS). Para a análise dos resultados, foi empregada a Análise Fatorial, Análise de Variância (ANOVA) e Análise de Cluster. Identificaram-se três grupos de empresas ou clusters, em que o Cluster 1 concentra as empresas de menor porte e com menor desempenho, e os demais clusters com desempenho superior. Além disso, os dados sugerem que empresas que pertencem ao Cluster 2 e ao Cluster 3, que conseguiram captar melhor o valor percebido dos clientes e optaram por uma estratégia de preços

\footnotetext{
* Universidade de Caxias do Sul. esaciloto4@gmail.com .

** Universidade de Caxias do Sul. Programa de Pós-Graduação em Administração. flarenti@ucs.br.

*** Universidade de Caxias do Sul. Programa de Pós-Graduação em Administração. gsmilan@ucs.br .

**** Universidade de Caxias do Sul. Programa de Pós-Graduação em Administração. deonirdt@terra.com.br .
} 
altos, apresentam melhor desempenho diante dos principais concorrentes.

Palavras-chave: preço; decisões de preço; estratégias de preço; desempenho organizacional.

\section{Abstract}

This study verifies the formation of clusters of companies from their pricing strategies and performance levels. As a research method, a quantitative-descriptive survey research with those responsible for the process of pricing of 153 companies affiliated to Metal-mechanic Factory Association of Caxias do Sul was performed. For the analysis of the results, Factor Analysis, Analysis of Variance (ANOVA) and Cluster Analysis were used. It was identified three companies' clusters, and the Cluster 1 concentrates the smaller companies with lower performance and the other clusters with superior performance. Furthermore, the data suggest that companies belonging to Cluster 2 and Cluster 3 , which could better capture the perceived value of customers and chose a high price strategy, performed better than their main competitors.

Keywords: price; price decisions; pricing strategies; organizational performance.

\section{INTRODUÇÃo}

O número de ofertas aumenta cada vez mais com competidores qualificados e novos entrantes, o que faz com que o preço represente um dos elementos mais importantes para a sustentabilidade de uma empresa no curto, médio e longo prazos (NICHELE; MILAN, 2006). Os clientes têm diferentes necessidades, desejos e expectativas, preferências e poder de compra, afetando, dessa forma, o seu comportamento de compra e a sua disposição em pagar diferentes níveis de preços pelos mesmos produtos e/ou serviços (KOHLI; SURI, 2011).

Para Dolan e Simon (1998), uma estratégia de precificação bem elaborada é capaz de explorar ao máximo as possibilidades que o mercado apresenta e, dessa forma, minimizar os possíveis efeitos negativos na empresa. Porém, também é necessário adotar estratégias e táticas que permitam à companhia se adequar rapidamente 
às constantes mudanças mercadológicas que possam vir a exigir certa flexibilidade nos preços (COELHO, 2007).

Conforme Ingenbleek, Frambach e Verhallen (2013), adotar práticas de preços inadequadas pode levar a um declínio no desempenho de um produto atual ou um novo produto e, até mesmo, do negócio como um todo, o que faz com que o efeito positivo da vantagem dos produtos que a empresa comercializa e de sua forma de atuação no mercado, sobre as variáveis dos resultados, seja minimizado ou desapareça. Para obter lucro, portanto, os gestores devem escolher uma estratégia e níveis de preços que sejam adequados ao posicionamento mercadológico da empresa e ao contexto competitivo em que está inserida, esforçando-se para praticar um preço justo (LAMB JR.; HAIR JR.; MCDANIEL, 2004; NICHELE; MILAN, 2006; HOOLEY; PIERCY; NICOLAUD, 2011).

Estudos sobre preço variam consideravelmente entre as indústrias (setores), países e tipos de clientes e/ou consumidores (compradores), dependendo de suas características e de seu perfil. Porém, as abordagens entre os pesquisadores podem ser classificadas, basicamente, em três grandes grupos: (i) preço com base em custos; (ii) preço com base na concorrência; e (iii) preço com base no valor para o cliente (HINTERHUBER, 2008).

No entanto, um gestor não pode considerar atribuir um preço de um produto e/ou serviço que não cubra os custos, tampouco considerar um preço baseado unicamente em custo e lucro, pois pode acabar sendo alto demais, ou baixo demais, tendo em vista as condições de mercado (SEMENIK; BAMOSSY, 1997). Nesse sentido, Ingenbleek et al. (2003) partem do pressuposto de que esses parâmetros podem ser utilizados concomitantemente, pois não são perspectivas mutuamente excludentes, mas sim até complementares.

Assim, não existe uma única forma de solucionar e organizar a precificação. Antes de definir o preço, a empresa deve decidir qual será sua estratégia para o produto bem, como quais serão os objetivos a serem alcançados, até porque quanto mais claros forem, mais fácil será o estabelecimento de preços (HINTERHUBER; LIOZU, 2013).

Segundo Hollensen (2006) e Saxena (2009), o preço não é um conceito único, mas multidimensional com diferentes significados e 
aplicações para o fabricante, o intermediário e o consumidor final. Nesse sentido, de acordo com Milan et al. (2013), os gestores devem entender o contexto da precificação em relação ao contexto mercadológico em que a empresa está inserida, principalmente a percepção de valor para o comprador e o preço praticado no mercado e sua influência no desempenho (performance) do negócio.

Pode-se afirmar, portanto, que corporações desenvolvem e executam estratégias de precificação de diferentes formas. No entanto, quais são essas diferenças? Que grupos de empresas podem ser constituídos a partir das estratégias de precificação e níveis de desempenho? Sendo assim, este trabalho tem por objetivo verificar a constituição de grupos de empresas a partir de suas estratégias de precificação e níveis de desempenho.

Em relação a isso, a forma como os gestores combinam suas estratégias para chegar a um preço final, bem como a influência das características da empresa, de sua estrutura e dos gestores envolvidos nas decisões sobre as estratégias de precificação continuam a ser importantes para o desenvolvimento de novas pesquisas (NOBLE; GRUCA, 1999; HINTERHUBER; LIOZU, 2012). A pesquisa, então, se justifica pela busca de melhor compreensão dos motivos que levam as organizações a utilizarem a precificação como forma de alavancar melhores resultados (NOBLE; GRUCA, 1999; NICHELE; MILAN, 2006; HOOLEY; PIERCY; NICOLAUD, 2011; KOHLI; SURI, 2011; HINTERHUBER; LIOZU, 2012; INGENBLEEK; FRAMBACH; VERHALLEN; 2013; LARENTIS et al., 2013; MILAN et al., 2013).

\section{REFERENCIAL TEÓRICO}

\subsection{Estratégias de precificação}

A estratégia de precificação, sob o ponto de vista do marketing estratégico, é definida como os planos que as empresas têm desenvolvido em relação a seus preços sendo estes observáveis no mercado, fornecendo um meio pelo qual a empresa elas podem atingir seu objetivo de preços (TELLIS, 1986; NOBLE; GRUCA, 1999; TORRES; MARTIN, 2006; INGENBLEEK; VAN DER LANS, 2013). Infelizmente, uma das áreas é frequentemente esquecida quando 
se trata de planejamento e implementação de estratégias e ações, e esta área diz respeito ao preço (LANCIONI, 2005).

De acordo com Nagle e Hogan (2007), a diferença entre a fixação convencional de preços e a precificação estratégica consiste em reagir às condições de mercado ou gerenciá-las proativamente; seu propósito é exercer o nível de preços mais lucrativo e rentável por meio da geração de mais valor aos clientes e à empresa, sem a obrigatoriedade de aumentar o volume de vendas (faturamento) dela. Por isso, uma estratégia de preços consistente deve avaliar e considerar as forças que moldam o mercado, a sensibilidade ao preço por parte dos clientes, as interações com a concorrência e a própria situação interna da companhia (TORRES; MARTINS, 2006; NAGLE; HOGAN, 2007).

Uma estratégia de preços fornece, portanto, uma definição sistemática dos elementos dela que devem ser gerenciados para obter um desempenho lucrativo e rentável em um negócio. Esses elementos incluem decisões dos clientes-alvo, identificação das ofertas adequadas para cada cliente-alvo, comunicação para convencê-los a partir de um processo de comunicação entre as partes e de negociação de vendas e uma metodologia de fixação de preços, estrutura organizatinal para realizar os processos de precificação e desenvolvimento de sistemas de informações gerenciais relacionados (CRESSMAN JR., 2012).

Com o objetivo de trazer maiores esclarecimentos sobre as estratégias de preços, Ingenbleek e Van der Lans (2013) utilizaram a teoria inerente ao planejamento de marketing para argumentar que a relação entre a estratégia de preço e as práticas de preço existe e é forte. Tal teoria distingue estágios nessa transição como formulação, implantação e avaliação da precificação (JAIN, 2004). Com esse ponto de vista, Ingenbleek e Van der Lans (2013) destacam a estratégia de preços como planos que as empresas têm desenvolvido em relação ao elemento de preço, e as práticas de preço como aquelas que podem ajudar a colocar esse plano formulado em funcionamento para a prática pretendida.

Para ampliar a compreensão acerca das estratégias de preço, o Quadro 1 demonstra as estratégias de precificação formuladas por Noble e Gruca (1999), que distinguem três situações de preço: preço 
de novos produtos e/ou serviços, preços competitivos e preços por linhas de produtos e/ou serviços. Ingenbleek e Van der Lans (2013) acrescentam os preços premium no contexto de preços competitivos e removem o preço baseado em custos por considerarem uma mera prática de preços.

Cabe ressaltar que a estratégia de precificação pela Internet é acrescentada pelos autores como algo novo, a qual não tem sido extensivamente abordada na literatura atinente ao tema. Isso se justifica devido ao aumento das transações comerciais ocorridas pelo ambiente virtual na última década. Os autores relatam, ainda, que estudos nessa área devem crescer em importância nos próximos anos (RAO; KARTONO, 2009).

Considerando que a estratégia de preços é o meio pelo qual a empresa pode alcançar o seu preço-alvo no mercado e respectivos resultados (NOBLE; GRUCA, 1999; TELLIS, 1986), a prática de preços diz respeito ao conjunto de atividades executadas pelos gestores que levam às decisões de preço para as operações do dia a dia com os seus clientes (INGENBLEEK et al., 2003). As práticas de preço ocorrem, portanto, dentro de um contexto de um processo organizacional pelo qual os gestores recolhem, partilham, interpretam e utilizam a informação para levar a uma decisão de preço cada vez mais assertiva. A principal diferença entre a estratégia de preços e as práticas de preço é que a primeira é observável no mercado, ao passo que as práticas de preço estão escondidas atrás dos limites de uma empresa, geralmente traduzidas por números (INGENBLEEK; VAN DER LANS, 2013).

A literatura de preços, muitas vezes, não faz distinção entre os dois termos. Vários estudos incluem conceitos que, de acordo com as definições anteriores, abordam a estratégia de precificação e as práticas de preços como sendo um mesmo construto e/ou em um mesmo nível de mensuração (INGENBLEEK; VAN DER LANS, 2013). Nesse sentido, Ingenbleek et al. (2003) e Monroe (2003) consideram três práticas em que os gerentes usam essas informações para a formação do preço-base - a percepção de valor para o cliente, a concorrência e os custos incorridos -, determinando-as como essenciais à prática de fixação de preços por lidar diretamente com a fixação de um valor quantitativo para as ofertas da empresa ao mercado. 
Quadro 1 - Estratégias de preço

\begin{tabular}{|c|c|c|c|}
\hline Situações & Estratégias & Descrição & Determinantes da Estratégia \\
\hline \multirow{7}{*}{ 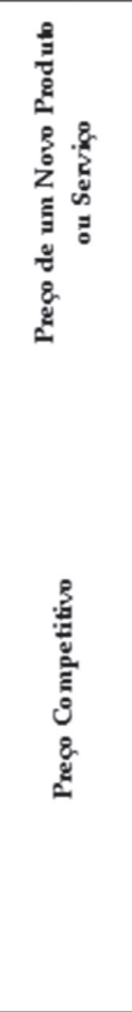 } & $\begin{array}{l}\text { Desnata } \\
\text { mento }\end{array}$ & $\begin{array}{l}\text { Alto preço inicial e } \\
\text { reduzido de forma } \\
\quad \text { sistem ática }\end{array}$ & $\begin{array}{l}\text { Alta diferenciaçãoda oferta (produto e/ou serviço), } \\
\text { demanda de mercadoinelástica, alta utilizaçãoda } \\
\text { capacidadee desvantagem de custos em funçãoda } \\
\text { escala }\end{array}$ \\
\hline & Penetração & $\begin{array}{l}\text { Preço inicial baixo para } \\
\text { acelerar a adoção do } \\
\text { produto ou do ser viço }\end{array}$ & $\begin{array}{l}\text { Baixa diferenciação da oferta no mer cado, vantagem de } \\
\text { custo em função da escala, baixa utilização da } \\
\text { capacidadee demanda de mercado elástica }\end{array}$ \\
\hline & $\begin{array}{l}\text { Curva de } \\
\text { Experiência }\end{array}$ & $\begin{array}{l}\text { Preço baixo para } \\
\text { reduzir custos }\end{array}$ & $\begin{array}{c}\text { Baixa diferenciação da oferta, vantagem de custoem } \\
\text { função da escala, baixa utilização da capacidadee } \\
\text { demanda de mercado elástica }\end{array}$ \\
\hline & $\begin{array}{l}\text { Lider de } \\
\text { Preços }\end{array}$ & $\begin{array}{l}\text { Inicia uma mudança } \\
\text { de preçose espera que } \\
\text { os cutros o sigam }\end{array}$ & $\begin{array}{l}\text { Alta participação de mercado, facilidade de detectar } \\
\text { mudanças de preços no mer cado, demanda inelástica, } \\
\text { alta utilização da capacidade e vantagens de custo, de } \\
\text { escala ede aprendizadoem termos de processos } \\
\text { e sobreo mercado de atuação }\end{array}$ \\
\hline & $\begin{array}{l}\text { Paridade } \\
\text { dePreços }\end{array}$ & $\begin{array}{l}\text { Preço fixado pelo } \\
\text { mercado global cu pelo } \\
\text { líder depreços }\end{array}$ & $\begin{array}{l}\text { Desvantagem de custos, baixa participação de mercado, } \\
\text { baixa diferenciaça da oferta no mercado, facilid ade de } \\
\text { detectar mudanças de preços, demanda de preços } \\
\text { inelástica, demanda de marca elástica e alta utilização } \\
\text { da capacidade }\end{array}$ \\
\hline & $\begin{array}{l}\text { Menor } \\
\text { Preço }\end{array}$ & $\begin{array}{l}\text { Possuir sempreque } \\
\text { possível omenor preço } \\
\text { do mercado }\end{array}$ & $\begin{array}{l}\text { Baixa utilização da capacidade, baixa participação de } \\
\text { mercado, baixa difer en ciação da oferta, vantagem } \\
\text { de custo, de escala e de aprendizado, dificuldade de } \\
\text { detectar mudanças de preço e demanda elástica }\end{array}$ \\
\hline & $\begin{array}{l}\text { Preço } \\
\text { Premium }\end{array}$ & $\begin{array}{l}\text { Preço mais alto } \\
\text { domercado, refletido } \\
\text { pela qualidadeda } \\
\text { oferta }\end{array}$ & $\begin{array}{l}\text { Alta diferenciação da oferta (produto e/ou serviço), } \\
\text { demanda de mercado inelástica, alta utilização da } \\
\text { capacidade e vantagem de custo em funçãoda escala }\end{array}$ \\
\hline \multirow{3}{*}{ 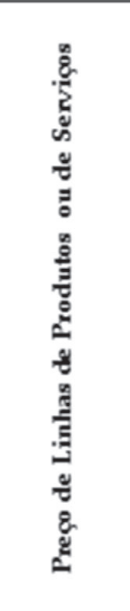 } & $\begin{array}{l}\text { Preçode } \\
\text { Produto ou } \\
\text { Serviço } \\
\text { Compleme } \\
\text { ntar }\end{array}$ & $\begin{array}{c}\text { Preço baixo para o } \\
\text { produto ou serviço } \\
\text { principal quando } \\
\text { ser viços } \\
\text { complem entares } \\
\text { possuem um preço } \\
\text { maior }\end{array}$ & Alto custo de m \\
\hline & $\begin{array}{l}\text { Preço por } \\
\text { Pacote }\end{array}$ & $\begin{array}{l}\text { Produto é parte de um } \\
\text { pacote de outros } \\
\text { produtos cndeo preço } \\
\text { proporcione uma } \\
\text { econcmia aos clientes }\end{array}$ & $\begin{array}{l}\text { Vantagem de custos } \\
\text { Demanda demercado elástica }\end{array}$ \\
\hline & $\begin{array}{l}\text { Valor para } \\
\text { oCliente }\end{array}$ & $\begin{array}{l}\text { Preço de uma versão } \\
\text { dos produtos a niveis } \\
\text { bastante competitivos } \\
\text { com menos } \\
\text { especificações }\end{array}$ & $\begin{array}{l}\text { Dificuldade em detectar mudanças de preços e } \\
\text { demanda do mercado elástica. }\end{array}$ \\
\hline
\end{tabular}

Fonte: Adaptada de Noble e Gruca (1999) e Ingenbleek e Van der Lans (2013). 
Segundo Hinterhuber (2008), os preços têm um impacto elevado sobre a lucratividade e a rentabilidade das empresas, e as estratégias para defini-los variam consideravelmente entre indústrias (setores) e situações de mercado. No entanto, pesquisadores geralmente concordam que as estratégias de preço podem ser categorizadas em três grandes grupos: (i) preços baseados em custos; (ii) preços baseados na concorrência; e (iii) preços baseados na percepção de valor para o cliente (NAGLE; HOLDEN, 2003).

Dessa forma, Nagle e Holden (2003) indicam que deve haver uma consideração equilibrada das informações, percepções ou comportamento dos 3Cs (Custos, Concorrentes e Clientes) como forma de atingir o preço ótimo. Administrar essas informações é um fator crucial para o sucesso na definição da estratégia de precificação e de formação dos preços. Essas práticas, na literatura de marketing, algumas vezes também são chamadas de métodos de fixação de preços (AVLONITIS; INDOUNAS, 2005).

O Quadro 2 resume as principais características das abordagens citadas. A vantagem dos dois primeiros métodos (custos e concorrência) é que os dados estão normalmente disponíveis prontamente, mas a desvantagem é que eles não levam em conta as necessidades dos clientes, ao contrário da abordagem de preços de valor percebido que os considera desde o início, no entanto são dados relativamente difíceis de se obter e interpretar (HINTERHUBER, 2008).

Dessa maneira, de acordo com Cressman Jr. (2012), o que constitui uma estratégia de precificação de sucesso gera debates entre profissionais e acadêmicos da área de marketing. Alguns argumentam que uma precificação de sucesso está na habilidade de se estabelecer um preço-alvo o qual os clientes concordem em pagar, ao passo que outros defendem que o sucesso está na habilidade de precificar bens e/ou serviços de maneira a aumentar a participação de mercado, o volume de negócios ou a preferência dos clientes.

\section{ESTRATÉGIAS DE PREÇO E O DESEMPENHO DO NEGÓCIO}

O preço é um dos principais determinantes para a escolha dos produtos e/ou serviços pelos compradores. Ao longo do tempo fatores como maior diferenciação das ofertas, desenvolvimentos tecnológicos e atrelados à inovação e a globalização da economia 
Quadro 2: Resumo das abordagens para fixação do preço

\begin{tabular}{|c|c|c|c|}
\hline Abordagens & $\begin{array}{c}\text { Precificação Baseada } \\
\text { em Cust os }\end{array}$ & $\begin{array}{c}\text { Precificação Baseada } \\
\text { na Concorrência }\end{array}$ & $\begin{array}{l}\text { Precificação Baseada } \\
\text { em Val or Percebido }\end{array}$ \\
\hline Definição & $\begin{array}{l}\text { Determinação dos } \\
\text { preços } \\
\text { principalmente com } \\
\text { dados da } \\
\text { contabilidade de } \\
\text { custos }\end{array}$ & $\begin{array}{c}\text { Utiliza os preços } \\
\text { observados de } \\
\text { concorrentes como fonte } \\
\text { primária para fixação dos } \\
\text { preços }\end{array}$ & $\begin{array}{l}\text { Usa o valor de um produto ou } \\
\text { serviço de entrega a um } \\
\text { segmento de dientes pré- } \\
\text { definido como principal fator } \\
\text { para fixar preços }\end{array}$ \\
\hline Exemplos & $\begin{array}{l}\text { Custo mais margem, } \\
\text { preços mark-up preço } \\
\text { alvo de retorno }\end{array}$ & $\begin{array}{l}\text { Paralelismo de preços, } \\
\text { preços guarda-chuva, } \\
\text { preços de penetração, } \\
\text { preços de acordo coma } \\
\text { média de mercado. }\end{array}$ & $\begin{array}{c}\text { Precificação de valor } \\
\text { percebido, desempenho } \\
\text { do preço }\end{array}$ \\
\hline $\begin{array}{l}\text { Pontos } \\
\text { Fortes }\end{array}$ & $\begin{array}{c}\text { Disponibilidade de } \\
\text { dados }\end{array}$ & Disponibilidade de dados & $\begin{array}{c}\text { Leva a perspectiva do cliente } \\
\text { em consideração }\end{array}$ \\
\hline $\begin{array}{l}\text { Pontos } \\
\text { Fracos }\end{array}$ & $\begin{array}{c}\text { Não leva a } \\
\text { compe tição } \\
\text { em conta. Não leva a } \\
\text { disponibilidade do } \\
\text { diente em pagar mais }\end{array}$ & $\begin{array}{l}\text { Não leva em conta a } \\
\text { disponibilidade } \\
\text { do diente em pagar mais }\end{array}$ & $\begin{array}{l}\text { Dados difíceis de obter e } \\
\text { interpretar, pode conduzir } \\
\text { a altos preços e necessidade } \\
\text { de levar em conta a } \\
\text { rentabilidade a longo prazo. }\end{array}$ \\
\hline $\begin{array}{l}\text { Avaliação } \\
\text { Geral }\end{array}$ & $\begin{array}{l}\text { Abordagem geral } \\
\text { mais fraca }\end{array}$ & $\begin{array}{l}\text { Abordagem sub-otimo } \\
\text { para a criação de preços, } \\
\text { apropriada para } \\
\text { commodities e produtos } \\
\text { que não possam ser } \\
\text { diferenciados }\end{array}$ & $\begin{array}{l}\text { Em geral melhor abordagem, } \\
\text { link direto para a necessidade } \\
\text { dos clientes. }\end{array}$ \\
\hline
\end{tabular}

Fonte: Adaptada de Hinterhuber (2008).

fizeram com que ele ganhasse maior relevância, pois é um dos elementos-chave para alcançar o volume de vendas desejado e impactar diretamente os lucros e a rentabilidade das empresas (MONROE, 2003).

De acordo com Hinterhuber (2004), o impacto do preço sobre a rentabilidade é alto, ou seja, a influência mesmo de pequenos aumentos de preço na lucratividade e na rentabilidade empresarial, de longe, excede o impacto de outras alavancagens de gestão de resultados. Em seu estudo, foi detectado que um aumento de 5\% em preços médios de vendas pode aumentar o lucro antes de juros e impostos EBIT (Earnings Before Interest and Taxes) em 22\% na média, em comparação ao aumento de $12 \%$ no volume de vendas e $10 \%$ na redução dos custos das mercadorias vendidas, respectivamente. 
Segundo Kohli e Suri (2011), de todos os elementos disponíveis para os gestores de marketing, o preço é o que possui maior impacto tanto nas linhas superiores quanto nas inferiores dos resultados das empresas, dadas as possíveis vantagens de serem obtidas que, se perseguidas com cuidado, podem trazer ganhos representativos. As companhias trabalham no sentido de reduzir - e, se possível, eliminar - custos, ao passo que o aumento de $1 \%$ nos preços de vendas pode trazer resultados bastante expressivos, desde que partindo-se do pressuposto que esse aumento não afetará o volume de vendas. O contrário também é verdadeiro, pois qualquer ocilação pode afetar a lucratividade e a rentabilidade das empresas, fazendo dos preços uma decisão crítica.

Os mesmos autores ainda relatam que outro grande problema é a interferência de outros grupos internos na organização. A área de marketing pode determinar os preços na comercialização em nível de estratégia, já a área de vendas (ou comercial), muitas vezes, controla preços no nível de transação, tendo em vista que algumas empresas possuem a remuneração da equipe de vendas baseada, em essência, no volume de negócios, ao contrário de estar baseada também na qualidade do resultado (abertura e manutenção de clientes, aumento da participação de mercado, maior cobertura de mercado, melhores margens de contribuição, lucro e rentabilidade). Desse modo, os vendedores não possuem muitos incentivos para negociar, defender e, efetivamente, cobrar um preço mais elevado, o que faz com que isso tenha um efeito contrário, ou seja, eles normalmente estão mais propensos a oferecer o máximo de descontos para os clientes, facilitando o processo das vendas.

De acordo com Dolan e Simon (1998) e Simon, Bilstein e Luby (2008), os gestores deveriam abandonar o raciocínio de maior participação de mercado e de maior volume de negócios em favor de uma visão mais orientada para o lucro. Os resultados indicam que as empresas que praticam um preço superior ao de seus concorrentes obtêm maior lucratividade e rentabilidade, o que provavelmente tem relação com a entrega de valor superior aos clientes, justificando a cobrança de preços maiores e, consequentemente, melhorando o desempenho do negócio. Às vezes os gestores são instigados realmente a almejar um preço competitivo, o que pode trazer vantagens 
perante os competidores. Porém, o objetivo central da precificação, sob a filosofia do marketing, não é o de as empresas simplesmente praticarem preços inferiores aos adotados por outros players, e sim maximizar o nível de valor para o cliente e, fundamentalmente, aumentar o lucro e a rentabilidade (HINTERHUBER, 2008; LARENTIS et al., 2013).

Nesse aspecto, o próprio preço pode ser uma das estratégias de competição e diferencial de mercado. Monroe e Cox (2001) apresentam alguns passos relevantes no sentido de melhorar a performance do negócio com base na precificação: (i) pesquisar o ambiente em que o preço será praticado para entender melhor os fatores que influenciam a dinâmica da oferta e da demanda, principalmente o processo de decisão de compra dos clientes e/ou consumidores; (ii) estabelecer a estratégia de precificação adequada ao posicionamento mercadológico desejado; e (iii) implantar as ações e os investimentos necessários e consistentes à estratégia e à política de preços preestabelecidas pela empresa.

Paralelamente, Liozu e Hinterhuber (2013a) desenvolveram um estudo com o objetivo de verificar se os métodos de precificação afetam o desempenho das empresas. Eles entrevistaram 1.812 profissionais envolvidos no processo de estabelecimento de preços, avaliando a orientação de preços a partir das escalas desenvolvidas por Ingenbleek et al. (2003), para medir a precificação baseada em valor, na concorrência e em custos, além de medir a capacidade dos preços e o desempenho das empresas em comparação aos concorrentes (crescimento das vendas, retorno sobre investimentos, retorno sobre as vendas, entre outros). Os resultados demonstraram que o preço baseado no valor percebido pelos clientes possui uma relação positiva com o desempenho das companhias, independentemente ao tamanho (porte) delas, indústria (setor de atuação) ou nacionalidade, mas não foi evidenciada tal relação com o preço baseado na concorrência. Os dados sugerem que as empresas que passarem a utilizar o preço baseado em valor podem ainda, melhorar seu desempenho. Além disso, os autores concluíram que as três orientações ou abordagens de preço influenciam diretamente a capacidade dos preços das empresas, que são positivamente relacionadas ao desempenho corporativo (LIOZU; HINTERHUBER, 2013a). 
No entanto, em um estudo realizado por Füreder, Maier e Yaramova (2014) em empresas de médio porte na Áustria, apenas 13\% das consideradas médias (50 a 249 funcionários) aplicavam alguma abordagem de preços baseada em valor percebido. O motivo apresentado para a não utilização era a competitividade do mercado (guerra de preços) que tornava difícil a diferenciação entre a concorrência; além disso, a tarefa de comunicar valor para o cliente também foi apontada como uma dificuldade, fazendo om que fosse difícil a diferenciação dos produtos. Desse modo, as empresas apresentaram um resultado com baixa margem de contribuição (entre 0 e $10 \%$ ). Por outro lado, as que utilizavam com maior frequência a precificação baseada em valor percebido possuíam maiores margens de contribuição (entre 11 e 30\%), e nenhuma foi encontrada com margens negativas.

Outro estudo realizado por Indounas (2014) em empresas prestadoras de serviço na Grécia, mais especificamente ligadas à logística, tecnologia da informação, consultorias e assessoria financeira, entre outras, buscou identificar o impacto da estratégia de precificação e o desempenho delas. Os resultados demonstraram que a orientação para o mercado influencia a precificação estratégica, ao passo que o tamanho da empresa, a posição dela no mercado e a intensidade competitiva não exercem qualquer influência.

Além disso, o autor dividiu a amostra em dois grupos: um utiliza uma estratégia de preços baixos, e outro, de preços altos. Os resultados indicaram que empresas com estratégias de preços altos apresentam melhores resultados do que as que optam por uma estratégia de preços baixos. Aquelas que escolheram uma estratégia de preços altos apresentaram melhor desempenho tanto em aspectos quantitativos, como rentabilidade, receita total, custos, quanto qualitativos, ou seja, satisfação e fidelidade do cliente, conhecimento da marca e grau de diferenciação (INDOUNAS, 2014).

Segundo Liozu e Hinterhuber (2013b), pesquisa feita com gestores de preços de empresas de manufatura localizadas predominantemente na América do Norte (68\%) e na Europa (24\%) para avaliar e entender os fatores organizacionais que influenciam a eficácia dos programas de preço indicou que o envolvimento da gestão no processo de fixação de preços é concentrado principalmente em 
expressar a convicção sobre a importância desse processo para a companhia, concentrando as decisões-chave atinentes ao processo de precificação na alta administração. $O$ estudo evidenciou também quatro competências-chave, as quais diferenciam o alto desempenho do baixo desempenho das empresas no que diz respeito à precificação: (i) confiança organizacional (convicção do valor associado a produtos e/ou serviços, confiança no futuro, sentimento de propósito e sentimento de ser capaz de assumir desafios); (ii) capacidade de preços (capacidade das empresas para quantificar o valor e a disposição do cliente em pagar; de monitorar os níveis de preços competitivos e reagir às mudanças no mercado; e de manter a estratégia e os preços); (iii) capacidade de mudança organizacional (adaptação mais rápida e de maneira mais eficaz do que os concorrentes às situações de mudanças impostas pelos compradores ou pelo mercado como um todo); e (iv) comportamento apoiador da alta administração (envolvendo a convicção sobre a importância das estratégias e do processo de estabelecimento de preços, com demonstração de confiança na tomada de decisão dos responsáveis pelo processo de precificação).

A pesquisa também identificou um conjunto de atividades que podem ser implementadas a fim de aumentar o desempenho das empresas: (i) atividades voltadas para a melhoria da eficácia dos preços (por exemplo, formação do preço com auxílio de ferramentas e análise de desempenho destes); (ii) melhorias e diferenciação da qualidade dos produtos e/ou serviços, inclusive as direcionadas à inovação; (iii) pesquisas ou levantamentos de informações para criação de valor para o cliente; (iv) aumento da sensação de confiança organizacional (por exemplo, otimismo, resiliência, "poder fazer", atitude); (v) melhorias na capacidade de manter o nível de preços desejado; (vi) minimização da concessão de descontos ou reduções de preços, mesmo que temporárias; (vii) maior capacidade de adaptação às mudanças de mercado; e (viii) apoio da alta administração, em que os gestores de todos os níveis são aconselhados e apoiados a realizar ações nos domínios acima citados (LIOZU; HINTERHUBER, 2013b).

Em relação a isso, de acordo com Cressman Jr. (1999), os gestores procuram reduzir custos para melhorar as margens de contribui- 
ção, lucratividade e rentabilidade; ou seja, gerir custos para ganhar produtividade deve ser uma ação regular em toda organização, mas a faixa de custos que pode ser reduzida tem limites, dadas as atividades essenciais à operação do negócio. Cabe salientar que muitas empresas não lidam bem com a determinação de preços, e entre os erros mais comuns nesse processo estão a excessiva orientação por custos, pouca frequência na revisão de preços para aproveitar as mudanças de mercado, preços determinados independentemente do restante dos elementos do composto de marketing (sem integração com o posicionamento mercadológico esperado) e rigidez dos preços para diferentes produtos e/ou serviços, segmentos ou nichos de mercado e vendas específicas.

\section{MÉTOdo DE PESQUISA}

A proposta de abordagem metodológica à questão central e aos objetivos de estudo consistiu na implementação de uma pesquisa quantitativa, de caráter descritivo (MALHOTRA; BIRKS; WILLS, 2012; REMLER; VAN RYZIN, 2011), por meio da realização de uma survey (FOWLER JR., 2009; FINK, 2013), de corte transversal único (FINK, 2013).

Para a sua implementação, como população-alvo foram consideradas indústrias afiliadas ao Sindicato das Indústrias Metalúrgicas, Mecânicas e de Material Elétrico de Caxias do Sul (SIMECS), no Rio Grande do Sul. A escolha se deu devido à vocação industrial da cidade, que se constitui em importante polo industrial. A população-alvo, de acordo com dados do SIMECS, compreendeu 730 empresas. Para a realização da pesquisa, utilizou-se uma amostra não probabilística, por conveniência (MALHOTRA; BIRKS; WILLS, 2012).

$\mathrm{O}$ instrumento de coleta de dados (questionário) se configura em uma versão revisada em relação aos estudos de Larentis et al. (2013) e Milan et al. (2013), a qual foi construída com base nas escalas propostas por Noble e Gruca (1999), para as estratégias de precificação; de Urdan (2005), para os fatores de definição de preços; e de Ingenbleek et al. (2003), para a avaliação da concorrência, do setor de atuação das empresas e do desempenho do negócio, operacionalizadas por meio de escalas do tipo Likert (FOWLER JR., 2009; HAWS; BEARDEN; NETEMEYER; 2011), de sete pontos, 
e não de cinco pontos, por haver indícios de melhoria no processo de coleta de dados ou das percepções dos respondentes (WEIJTERS; CABOOTER; SCHILLEWAERT, 2010; LARENTIS; GIACOMELLO; CAMARGO, 2012). Os blocos de questões a as escalas utilizadas são apresentados no Apêndice.

Das 74 variáveis inicialmente testadas, mediante os resultados estatísticos obtidos nos trabalhos anteriormente realizados (LARENTIS et al., 2013; MILAN et al., 2013), para a presente pesquisa, somente 61 foram consideradas, conferindo maior parcimônia no processo de coleta de dados, pois as eliminadas apresentaram falta de poder explicativo. Nesse processo, a partir das evidências empíricas, foi utilizado o procedimento de validação de conteúdo, ou validação de face, conforme recomendações encontradas na literatura (MALHOTRA; BIRKS; WILLS, 2012). Para tanto, essa nova versão do instrumento de coleta de dados passou pela análise e modificações implementadas por três professores doutores (experts), pesquisadores ligados à área de marketing.

Como procedimento de adequação e finalização do instrumento de coleta de dados, foi aplicado um preteste (MALHOTRA; BIRKS; WILLS, 2012) a um grupo de 12 respondentes que não indicaram necessidade de ajustes no questionário. Vale ressaltar que os questionários resultantes do preteste não foram incorporados à amostra final da pesquisa.

Em seguida, os questionários foram enviados eletronicamente às empresas da população-alvo definida. Juntamente com ele foi incluído um texto explicativo, solicitando direcionamento ao responsável pela definição de preços da empresa ou que atuasse diretamente no processo de precificação. Dessa maneira, utilizou-se o método de coleta de dados autoadministrado, ou seja, de autopreenchimento (FOWLER JR., 2009; FINK, 2013). A coleta de dados foi realizada entre os meses de junho e agosto de 2014, e o questionário foi enviado para as 730 empresas identificadas (população-alvo), obtendo-se um retorno de 157 questionários (casos válidos) - o equivalente a 21,5\%.

O questionário está dividido em blocos de questões (vide Apêndice), e para a análise dos dados, para cada um desses blocos foi utilizada a Análise Fatorial, pelo método dos componentes principais para extração dos fatores, com rotação ortogonal do tipo Varimax 
(JOHNSON; WICKERN, 2007; MULAIK, 2010; FIELD, 2013). Também se recorreu à Análise de Clusters, tendo em vista a formação de conglomerados a partir das características e comportamentos de precificação, bem como à Análise de Variância - ANOVA (HAIR JR. et al., 2009; FIELD, 2013).

Antes disso, para a definição da amostra final, foram analisados, inicialmente, os missings (não respostas), tendo como critérios o máximo de $10 \%$ por variável e a aleatoriedade na não resposta, utilizando-se em seguida método de substituição pela média, conforme recomendações (HAIR JR. et al., 2009; ENDERS, 2010), e dos outliers (dados atípicos) univariados, pelos $Z$ scores, e multivariados, pela distância de Mahalanobis (D2) (HAIR JR. et al., 2009). Sendo assim, dos 157 casos coletados, 4 foram eliminados pela incidência de outliers multivariados, resultando em 153 casos válidos. Identificou-se ademais a normalidade nos dados, dentro dos patamares indicados por Kline (2011) de assimetria (até |3| - na pesquisa o máximo foi de $|2,1|$ ) e de curtose (até $|10|$ - na pesquisa o máximo foi de $|4,8|)$.

\section{RESUltados}

\subsection{Caracterização da amostra}

Caracterizou-se a amostra a partir de 12 variáveis categóricas: cargo ou função que o respondente desempenha na empresa; tempo de atuação na empresa; ramo principal de atividade exercida pela empresa; tempo de atuação no mercado; número de funcionários; número atual de itens produzidos; faturamento anual bruto; tempo médio dos produtos no mercado; número de lançamentos de novos produtos; margem líquida de lucro; atuação em vendas no mercado externo; e se a empresa importa.

Quanto ao cargo ou função desempenhada nas empresas pesquisadas, $13 \%$ dos respondentes são proprietários delas e $12 \%$ possuem o cargo de diretor. Um número mais expressivo de participantes se encontra ligado à área comercial, os quais estão distribuídos nas funções de diretores, gerentes e coordenadores, o que representa $32 \%$ da amostra. Já a área financeira foi representada por 10\% dos respondentes, distribuindo-se entre os cargos de gerentes e coordenadores. 
Sobre o ramo de atividade das empresas, a maior parte $(54,9 \%)$ pertence ao metalúrgico, seguido pelo automotivo $(23,5 \%)$ e o eletroeletrônico (21,6\%). Elas apresentam, em média, 21 anos de atuação no mercado - 38\% possuem mais de 20 anos de atuação, e $40 \%$ se encontram na faixa entre 10 e 20 anos. No que se refere ao número de funcionários, 35,3\% contam com até 19 funcionários, e $37,9 \%$ possuem entre 20 e 100 funcionários; nas demais (26,8\%) são mais de 100 .

Das empresas pesquisadas, $24,2 \%$ possuem um faturamento anual bruto de R $\$$, 4 milhões e são caracterizadas, pelos critérios do BNDES, como microempresas; $34 \%$ faturam anualmente até R\$ 16 milhões e são pequenas empresas; $25,5 \%$ possuem faturamento de até $\mathrm{R} \$ 90$ milhões e são médias empresas; 9,2\% alcançam faturamento entre $\mathrm{R} \$ 90$ milhões a $\mathrm{R} \$ 300$ milhões e são médias-grandes empresas; e 7,2\% delas possuem faturamento acima de R $300 \mathrm{mi}-$ lhões e são grandes empresas.

No que diz respeito aos produtos fabricados e comercializados pelas empresas, $64,1 \%$ delas possuem produtos com tempo médio de mercado de até cinco anos, e 35,9\% acima desse tempo. Em relação ao lançamento de novos produtos, 34,6\% declararam ter lançado até três produtos novos nos últimos dois anos, 28,8\% entre três e dez produtos e 36,6\% mais que dez produtos. Quanto à margem líquida de lucro do último exercício, 2,6\% das empresas declararam que foi negativa (prejuízo), já 54,9\% revelaram uma margem líquida de lucro de até $10 \%$. Identificou-se, ainda, que 39,9\% são exportadoras e $52,3 \%$, importadoras.

\subsection{Estratégias de precificação nas empresas}

Dentro das estratégias de precificação, consideraram-se, além das estratégias propriamente ditas (variáveis V19 a V30 do questionário - vide Apêndice), os aspectos associados ao processo de formação de preços para os principais produtos das empresas pesquisadas (variáveis V1 a V15). Foram obtidos três fatores após a eliminação das variáveis V7, V14 e V15, em função de a carga fatorial estar abaixo de 0,5: F1 - Preço baseado na concorrência; F2 - Preço baseado em valor percebido; F3 - Preço baseado em custos. A variância explicada com esses três fatores foi de 63,75\%, 
o teste KMO foi de 0,790, e o teste de esfericidade de Bartlett com significância ao nível de 0,001, apresentando, assim, níveis adequados (JOHNSON; WICKERN, 2007). O Alpha de Cronbach, que em estudos exploratórios, como é o caso desta pesquisa, deve ser de 0,60 ou mais (MALHOTRA; BIRKS; WILLS, 2012). Somente o Fator 3 ficou levemente abaixo dessa recomendação, ao passo que os outros apresentaram valores satisfatórios (vide Tabela 1).

Tabela 1: Fatores relacionados à formação de preços nas empresas

\begin{tabular}{|c|c|c|c|c|c|}
\hline $\begin{array}{l}\text { Fatores relacionados } \\
\text { à formação de preços }\end{array}$ & Variáveis & $\begin{array}{l}\text { Cargas } \\
\text { fatoriais }\end{array}$ & $\begin{array}{l}\text { Alpha de } \\
\text { Cronbach }\end{array}$ & Média & $\begin{array}{l}\text { Desvio } \\
\text {-padrão }\end{array}$ \\
\hline \multirow{4}{*}{$\begin{array}{l}\text { F1: Preço baseado } \\
\text { na concorrência }\end{array}$} & V09 & 0,847 & \multirow{4}{*}{0,83} & \multirow{4}{*}{5,14} & \multirow{4}{*}{1,13} \\
\hline & V05 & 0,798 & & & \\
\hline & V08 & 0,775 & & & \\
\hline & $\begin{array}{l}\text { V06 } \\
\text { V10 }\end{array}$ & $\begin{array}{l}0,755 \\
0,619\end{array}$ & & & \\
\hline \multirow{4}{*}{$\begin{array}{l}\text { F2: Preço baseado } \\
\text { em valor percebido }\end{array}$} & V01 & 0,855 & \multirow{4}{*}{0,85} & \multirow{4}{*}{5,76} & \multirow{4}{*}{0,96} \\
\hline & V04 & 0,850 & & & \\
\hline & V02 & 0,809 & & & \\
\hline & V03 & 0.740 & & & \\
\hline \multirow{3}{*}{$\begin{array}{l}\text { F3: Preço baseado } \\
\text { em custos }\end{array}$} & V11 & 0,766 & \multirow{3}{*}{0,59} & \multirow{3}{*}{6,24} & \multirow{3}{*}{0,75} \\
\hline & V13 & 0,716 & & & \\
\hline & V12 & 0,711 & & & \\
\hline
\end{tabular}

Obs.: Média calculada a partir de uma escala de sete pontos.

Fonte: Elaborado pelos autores.

As variáveis V19 a V30 se referem às estratégias de precificação adotadas pelas empresas. Em função das cargas fatoriais inferiores a 0,5, foram eliminadas as variáveis V20, V24, V27 e V28.

Foram identificados, portanto, dois fatores Estratégia de Preços Baixos (F1) e Estratégias de Preços Altos (F2), conforme mostra a Tabela 2. Os dois fatores obtiveram um percentual de 59,6\% da variância explicada, muito próximo do limite recomendado por Hair Jr. et al. (2009), que sugere fatores suficientes para atender a um percentual de variância explicada de $60 \%$ ou mais. O teste KMO foi de 0,772, e o de esfericidade de Bartlett resultou em uma significância ao nível de 0,001, considerados níveis adequados, bem como o Alfa de Cronbach para os dois fatores. 
Tabela 2: Estratégia de precificação das empresas

\begin{tabular}{|c|c|c|c|c|c|}
\hline $\begin{array}{l}\text { Estratégias de } \\
\text { precificação }\end{array}$ & Variáveis & $\begin{array}{l}\text { Cargas } \\
\text { fatoriais }\end{array}$ & $\begin{array}{l}\text { Alpha de } \\
\text { Cronbach }\end{array}$ & Média & $\begin{array}{l}\text { Desvio } \\
\text {-padrão }\end{array}$ \\
\hline \multirow{3}{*}{$\begin{array}{l}\text { F1: Estratégia de } \\
\text { Preços Baixos }\end{array}$} & V21 & 0,871 & \multirow{3}{*}{0,82} & \multirow{3}{*}{2,83} & \multirow{3}{*}{1,51} \\
\hline & V22 & 0,870 & & & \\
\hline & V29 & 0,776 & & & \\
\hline \multirow{5}{*}{$\begin{array}{l}\text { F2: Estratégias de } \\
\text { Preços Altos }\end{array}$} & V23 & 0,761 & \multirow{5}{*}{0,72} & \multirow{5}{*}{4,11} & \multirow{5}{*}{1,23} \\
\hline & V26 & 0,712 & & & \\
\hline & V30 & 0,644 & & & \\
\hline & V19 & 0,617 & & & \\
\hline & V25 & 0,567 & & & \\
\hline
\end{tabular}

Obs.: Média calculada a partir de uma escala de sete pontos.

Fonte: Elaborada pelos autores.

O fato de as empresas concordarem mais com uma estratégia de preços altos e menos com a estratégia de preços baixos (Teste t, sig. $<0,001)$ pode estar ligado às características do mercado em que atuam, uma vez que muitos clientes utilizam os preços como indicador de qualidade.

\subsection{Níveis de desempenho}

Foram considerados fatores ligados ao desempenho de novos produtos o desempenho em relação aos concorrentes e outros aspectos ambientais que dizem respeito ao mercado de atuação das empresas. As variáveis V16 a V18 tratam do grau de concordância relativo ao desempenho de um novo produto comercializado. Para essas variáveis, obteve-se um único fator com variância explicada de $72,79 \%$, teste $\mathrm{KMO}$ de 0,688 em nível muito próximo ao adequado, e teste de esfericidade de Bartlett com significância ao nível de 0,001 . Todas as cargas fatoriais estão acima de 0,68 e o Alfa de Cronbach em 0,78. O único fator identificado foi denominado F1 (Desempenho do Novo Produto). Para tal, a média das variáveis apontou uma média de 5,49.

Além disso, as variáveis V31 a V33 formaram, também, um único fator, denominado F2 (Objetivo do Novo Produto), com variância explicada 78,6\%, teste $\mathrm{KMO}$ de 0,698, em níveis muito próximos do adequado e o de esfericidade de Bartlett com significância ao nível 
de 0,001 . Todas as cargas fatoriais resultaram em níveis adequados, ou seja, acima de 0,5 , e o Alfa de Cronbach em 0,82. Da mesma forma, a média das variáveis resultou em uma média de 5,41.

O desempenho em relação aos concorrentes foi constituído pelas variáveis V34 a V48, procurando-se verificar a performance das empresas em relação ao seu concorrente principal. Por meio da Análise Fatorial, e após a eliminação da variável V41, com carga fatorial abaixo de 0,5 , obtiveram-se quatro fatores com variância explicada de $72,1 \%$, assim como o teste $\operatorname{KMO}(0,851)$ e o teste de esfericidade de Bartlett, com significância ao nível de 0,001, bem como os Alphas de Cronbach. Tais resultados são apresentados na Tabela 3. A análise resultou em quatro fatores: F1 (Competitividade); F2 (Mercado); F3 (Custos); e F4 (Margem de Contribuição).

Tabela 3: Desempenho da empresa em comparação ao principal concorrente

\begin{tabular}{|c|c|c|c|c|c|}
\hline $\begin{array}{l}\text { Desempenho da empresa } \\
\text { em comparação ao } \\
\text { principal concorrente }\end{array}$ & Variáveis & $\begin{array}{l}\text { Cargas } \\
\text { fatoriais }\end{array}$ & $\begin{array}{l}\text { Alpha de } \\
\text { Cronbach }\end{array}$ & Média & $\begin{array}{l}\text { Desvio } \\
\text {-padrão }\end{array}$ \\
\hline \multirow{6}{*}{ F1: Competitividade } & V46 & 0,832 & \multirow{6}{*}{0,87} & \multirow{6}{*}{4,42} & \multirow{6}{*}{1,26} \\
\hline & $\mathrm{V} 40$ & 0,826 & & & \\
\hline & V36 & 0,776 & & & \\
\hline & V48 & 0,762 & & & \\
\hline & V35 & 0,627 & & & \\
\hline & V47 & 0564 & & & \\
\hline \multirow{4}{*}{ F2: Mercado } & V42 & 0,751 & \multirow{4}{*}{0,77} & \multirow{4}{*}{5,05} & \multirow{4}{*}{0,97} \\
\hline & V37 & 0,648 & & & \\
\hline & V43 & 0,573 & & & \\
\hline & V34 & 0,539 & & & \\
\hline \multirow{2}{*}{ F3: Custos } & V39 & 0,890 & \multirow{2}{*}{0,92} & \multirow{2}{*}{4,48} & \multirow{2}{*}{1,29} \\
\hline & V38 & 0,821 & & & \\
\hline \multirow{2}{*}{$\begin{array}{l}\text { F4: Margem } \\
\text { de contribuição }\end{array}$} & V45 & 0,893 & \multirow{2}{*}{0,77} & \multirow{2}{*}{4,74} & \multirow{2}{*}{0,96} \\
\hline & V44 & 0,762 & & & \\
\hline
\end{tabular}

Obs.: Média calculada a partir de uma escala de sete pontos.

Fonte: Elaborada pelos autores. 
Além disso, a variáveis V49 à V61 estão relacionadas às características intrínsecas ao principal mercado em que as empresas pesquisadas atuam. Nesta etapa da Análise Fatorial, foram obtidos três fatores após a eliminação das variáveis V49, V58 e V61: F1: Competitividade no Mercado de Atuação, F2: Desempenho do Mercado de Atuação e F3: Custos do Mercado de Atuação. Estes três fatores corresponderam a $68,1 \%$ da variância explicada. O teste $\mathrm{KMO}$ foi de 0,678, muito próximo ao nível adequado, o teste de esfericidade de Bartlett apresentou significância ao nível de 0,00 e todos os Alpha de Cronbach foram satisfatórios, conforme indica a Tabela 4.

Tabela 4: Aspectos relacionados ao mercado de atuação das empresas

\begin{tabular}{|c|c|c|c|c|c|}
\hline $\begin{array}{l}\text { Aspectos relacionados } \\
\text { ao mercado de atuação } \\
\text { das empresas }\end{array}$ & Variáveis & $\begin{array}{l}\text { Cargas } \\
\text { fatoriais }\end{array}$ & $\begin{array}{l}\text { Alpha de } \\
\text { Cronbach }\end{array}$ & Média & $\begin{array}{l}\text { Desvio } \\
\text {-padrão }\end{array}$ \\
\hline \multirow{5}{*}{$\begin{array}{l}\text { F1: Competitividade } \\
\text { no mercado de atuação }\end{array}$} & V59 & 0,799 & \multirow{5}{*}{0,80} & \multirow{5}{*}{5,19} & \multirow{5}{*}{0,86} \\
\hline & V51 & 0,723 & & & \\
\hline & V52 & 0,722 & & & \\
\hline & V50 & 0,714 & & & \\
\hline & V60 & 0,695 & & & \\
\hline \multirow{3}{*}{$\begin{array}{l}\text { F2: Desempenho } \\
\text { do mercado de atuação }\end{array}$} & V56 & 0,751 & \multirow{3}{*}{0,77} & \multirow{3}{*}{4,50} & \multirow{3}{*}{0,96} \\
\hline & V57 & 0,648 & & & \\
\hline & V53 & 0,573 & & & \\
\hline \multirow{2}{*}{$\begin{array}{l}\text { F3: Custos } \\
\text { no mercado de atuação }\end{array}$} & V54 & 0,890 & \multirow{2}{*}{0,85} & \multirow{2}{*}{5,32} & \multirow{2}{*}{0,82} \\
\hline & V55 & 0,821 & & & \\
\hline
\end{tabular}

Obs.: Média calculada a partir de uma escala de sete pontos.

Fonte: Elaborada pelos autores.

\subsection{Classificação dos grupos de empresas por desempenho}

Com o fim de identificar e obter agrupamentos (cluster) de empresas com características semelhantes, a partir dos fatores obtidos na Análise Fatorial, foi efetuada a Análise de Cluster (ou de Conglomerado). O objetivo primário dessa técnica é reduzir o número de indivíduos a grupos que sejam mutuamente excludentes, mas preservem as características de seus representantes (HAIR JR. et al., 2009; MALHOTRA, 2012). 
Para tanto, este estudo utilizou para a Análise de Cluster o método K Means Cluster, um método não hierárquico de aglomeração que consiste na transferência de um indivíduo para o cluster cujo centroide se encontra a menor distância. Esse método é bastante utilizado pela sua facilidade de aplicação perante um elevado número de observações.

Quanto à determinação da quantidade de agrupamentos, Malhotra (2012), Hair Jr. et al. (2009) e Vicini e Souza (2005) concordam que não existe um procedimento padrão para a identificação da quantidade adequada de agrupamentos, ficando esta a cargo dos pesquisadores. No entanto, há uma recomendação em Hair Jr. et al. (2009) sobre a conveniência de realizarem-se ao menos três execuções: com dois, três e quatro agrupamentos. Para este estudo também foram testados soluções com dois e quatro agrupamentos. No final optou-se pela solução com três agrupamentos.

As diferenças entre os grupos encontradas foram verificadas com a ajuda da Análise de Variância (ANOVA), considerando os fatores oriundos da Análise Fatorial como variáveis dependentes, e os grupos formados como variáveis independentes, cujo resultados estão reportados na Tabela 5 .

O Cluster 1 caracteriza-se quanto ao aspecto definição de Preços Baseados em Custos, fato identificado nos demais clusters também. Porém, apresenta-se com menor intensidade em relação aos outros. Quanto à estratégia de preços praticada pelo Cluster 1, destaca-se pela utilização de uma estratégia de preços voltada para a prática de preços baixos, o que pode estar associado a seu desempenho em relação ao seu principal concorrente, demonstrando obter um desempenho mais baixo em relação aos outros clusters identificados.

De forma geral, percebe-se que o Cluster 1 agrupa empresas que atuam em um mercado competitivo. Desse modo, o ambiente competitivo delas propicia a prática de preços baixos, tornando mais baixo o seu desempenho em relação aos concorrentes. Além disso, revela que em lançamentos de novos produtos não há um desempenho satisfatório, o que resulta em um baixo atingimento dos objetivos quando um novo produto é introduzido no mercado.

O Cluster 2, por sua vez, se caracteriza por utilizar a definição de Preços Baseados em Valor Percebido, fato também observado no 
Cluster 3, cujas médias apresentam-se muito próximas. No entanto, apesar de o Cluster 2 não mostrar níveis de significância quanto ao método de definição de preços, predomina a definição de Preços Baseados em Custos.

Tabela 5: Médias dos clusters identificados

\begin{tabular}{|c|c|c|c|c|}
\hline \multirow{2}{*}{ Fatores obtidos } & \multirow{2}{*}{$\begin{array}{l}\text { Mé- } \\
\text { dia }\end{array}$} & \multicolumn{3}{|c|}{ Clusters identificados } \\
\hline & & 1 & 2 & 3 \\
\hline F1: Preço Baseado na Concorrência & 5,14 & 5,18 & 4,99 & 5,52 \\
\hline F2: Preço Baseado em Valor Percebido & 5,76 & $4,73 a, b$ & $5,99 a$ & $6,05 b$ \\
\hline F3: Preço Baseado em Custos & 6,24 & $5,91 \mathrm{a}$ & 6,27 & $6,46 b$ \\
\hline F1: Estratégia de Preços Baixos & 2,83 & $4,61 \mathrm{a}, \mathrm{b}$ & $2,10 a$ & $3,20 \mathrm{~b}$ \\
\hline F2: Estratégias de Preços Altos & 4,11 & $2,75 a, b$ & $4,47 a$ & $4,36 \mathrm{~b}$ \\
\hline $\begin{array}{l}\text { F1: Comparação com Principal Concor- } \\
\text { rente-Competitividade }\end{array}$ & 4,42 & $3,18 a, b$ & $4,35 \mathrm{a}$ & $5,72 b$ \\
\hline $\begin{array}{l}\text { F2: Comparação com Principal Concor- } \\
\text { rente-Mercado }\end{array}$ & 5,05 & , b & $5,24 a$ & $5,64 b$ \\
\hline $\begin{array}{l}\text { F3: Comparação com Principal Concor- } \\
\text { rente-Custos }\end{array}$ & 4,48 & $3,65 a$ & $4,25 b$ & $5,86 a, b$ \\
\hline $\begin{array}{l}\text { F4: Comparação com Principal Concor- } \\
\text { rente-Margens de Contribuição }\end{array}$ & 4,74 & $3,81 a, b$ & $4,79 a$ & $5,42 b$ \\
\hline $\begin{array}{l}\text { F1: Competitividade no mercado de } \\
\text { atuação }\end{array}$ & 5,19 & $5,87 a$ & $4,77 a, b$ & $5,73 b$ \\
\hline F2: Desempenho do Mercado de Atuação & 4,51 & $4,12 a$ & $4,17 \mathrm{~b}$ & $5,77 \mathrm{a}, \mathrm{b}$ \\
\hline F3: Custos do Mercado de Atuação & 5,32 & $5,55 a$ & $5,14 a, b$ & $5,61 b$ \\
\hline F1: Desempenho do Novo Produto & 5,49 & $4,00 a, b$ & $5,69 \mathrm{a}$ & $6,30 \mathrm{~b}$ \\
\hline F2: Objetivo do Novo Produto & 5,10 & $3,84 a, b$ & $5,38 a$ & $5,51 b$ \\
\hline
\end{tabular}

Obs: a, b, c - diferenças significantes entre pares ao nível de 0,05.

Fonte: Elaborada pelos autores.

O Cluster 2 difere dos demais por ser o que agrupa empresas que mais discordam com uma Estratégia de Preços Baixos; desse modo, tende a concordar mais com uma Estratégia de Preços Altos. Ademais, seu desempenho em relação aos concorrentes aparece como intermediário em relação aos demais clusters. Além disso, o 
Cluster 2 sugere que o desempenho de mercado em que as empresas atuam é um pouco melhor em relação aos demais clusters.

Quanto ao lançamento de novos produtos, o Cluster 2 indica que os produtos das empresas possuem um desempenho um pouco melhor que o Cluster 1, fazendo com que os objetivos definidos no lançamento de novos produtos sejam alcançados.

Por fim, ao se analisarem as características do Cluster 3 evidencia-se uma semelhança de comportamento com o Cluster 2, porém, com maiores médias. Quanto à definição de preços, o Cluster 3 é o que mostra a maior concordância com a definição de Preços Baseadas em Custos e Preços Baseados e em Valor Percebido em níveis significativos em relação ao Cluster $\mathbf{1}$.

Em relação às estratégias de preços, o Cluster 3 demonstra não utilizar Estratégia de Preços Baixos, porém em menor intensidade que o Cluster 2. Isso pode sugerir que o Cluster 3 poderia utilizar uma Estratégias de Preços Baixos em alguma situação de seu interesse, pois seu grau de concordância com a definição de Preços Baseado em Custos é a maior dentre os demais clusters, o que sugere melhor domínio de seus custos.

Em relação ao seu principal concorrente, as empresas agrupadas no Cluster 3 revelam ter melhor desempenho em relação à competitividade, ao mercado, aos custos e às margens líquidas de lucro. Tal fato pode estar associado por perceberem que o mercado possui melhor desempenho dentre os demais clusters.

De forma geral, percebe-se o Cluster 3 como o que apresenta o melhor desempenho em relação aos demais, inclusive quanto aos lançamentos de novos produtos, pois demonstram que o desempenho do novo produto, bem como os objetivos relacionados, tendem a ser o melhor dentre os outros clusters. Sendo assim, os lançamentos de novos produtos proporcionam uma definição de Preços Baseada em Valor Percebido. Isso, por outro lado, pode trazer maior importância aos custos incorridos com o desenvolvimento e o lançamento desses produtos, o que faz com que a empresa possa combinar os dois métodos (Preço Baseado em Custos e Preço Baseado em Valor Percebido) para a decisão dos preços desses novos produtos como forma de recuperar os investimentos realizados neles. 
Com o objetivo de encontrar as características das empresas que compõem os clusters formados e assim identificar quais apresentam um desempenho diferenciado, pode-se usar, conforme proposto por Hair Jr. et al. (2009), a inclusão de dados não utilizados na composição original dos agrupamentos. Desse modo, optou-se por analisar por meio das variáveis, ramo de atividade, número de funcionários, clientes ativos nos últimos doze meses, margem líquida de lucro, faturamento bruto anual, tempo médio dos produtos no mercado, lançamentos de novos produtos, empresas exportadoras e empresas importadoras em relação aos clusters formados (agrupamentos formados).

Assim, utilizou-se a tabulação cruzada por ser um método simples na descrição de conjuntos de relações em que as respostas para cada conjunto são tabuladas e avaliadas. Para tal, utiliza-se do teste qui-quadrado para examinar a existência de diferenças estatísticas entre esses grupos (HAIR JR. et al., 2009). A Tabela 6 (veja na página seguinte) contém os resultados comparando os perfis das empresas com os clusters identificados; além disso faz uma comparação com a quantidade de empresas que se encontram em cada categoria das variáveis, distribuindo-as entre cada cluster.

O Cluster 1 caracteriza-se principalmente por empresas ligadas ao ramo metalmecânico com até 19 funcionários e possui em média menos de 500 clientes ativos. O faturamento anual bruto é menor que 16 milhões, e com margens líquidas de lucro menores que 10\% (a metade declarou ter uma margem de lucro líquido inferior a 5\%).

Essas empresas possuem produtos com menos de cinco anos de mercado e lançam menos que três produtos novos por ano; a maior parte não possui receitas vindas do mercado externo e depende do mercado interno para suas vendas. Em aspectos gerais, os dados demonstram que o Cluster 1 é formado praticamente por empresas pequenas e com margens líquidas de lucro menores que $5 \%$, participando de um mercado competitivo, com forte atuação da concorrência e custos altos, praticando uma Estratégia de Preços Baixos, dada a competitividade observada nesse grupo. Desse modo, percebe-se que esse cluster possui o menor desempenho entre os demais. 
Tabela 6: Caracterização dos clusters identificados

Clusters identificados

\begin{tabular}{|c|c|c|c|c|c|c|c|c|c|}
\hline \multirow{2}{*}{\multicolumn{2}{|c|}{$\begin{array}{l}\text { Variáveis categóricas } \\
\text { n }\end{array}$}} & \multicolumn{2}{|c|}{$1(n=30)$} & \multicolumn{2}{|c|}{$2(\mathrm{n}=90)$} & \multicolumn{2}{|c|}{$3(n=33)$} & \multirow{2}{*}{\begin{tabular}{|l} 
Total \\
2 \\
\end{tabular}} & \multirow[t]{2}{*}{ Sig. } \\
\hline & & \multirow{2}{*}{\begin{tabular}{|l|}
$\%$ \\
24 \\
\end{tabular}} & & \multirow{2}{*}{$\%$} & & \multirow{2}{*}{\begin{tabular}{|l|}
$\%$ \\
21 \\
\end{tabular}} & & & \\
\hline \multirow{4}{*}{$\begin{array}{l}\text { Ramo principal } \\
\text { de atividade }\end{array}$} & Metalmecânico & & & & & & & 84 & \multirow{3}{*}{0,04} \\
\hline & Automotivo & 4 & 11,1 & 24 & 66,7 & 8 & 22,2 & 36 & \\
\hline & Eletroeletrônico & 2 & 6,1 & 27 & 81,8 & 4 & 12,1 & 33 & \\
\hline & Total & 30 & 19,6 & 90 & 58,8 & 33 & 21,6 & 153 & \\
\hline \multirow{4}{*}{$\begin{array}{l}\text { Número de fun- } \\
\text { cionários }\end{array}$} & $<19$ & 18 & 33,3 & 32 & 59,3 & 4 & 7,4 & 54 & \multirow{3}{*}{0,00} \\
\hline & 20 a 100 & 7 & 12,1 & 40 & 69,0 & 11 & 19,0 & 58 & \\
\hline & $>100$ & 5 & 12,2 & 18 & 43,9 & 18 & 24,6 & 41 & \\
\hline & Total & 30 & 19,6 & 90 & 58,8 & 33 & 21,6 & 153 & \\
\hline \multirow{4}{*}{$\begin{array}{l}\text { Clientes ativos } \\
\text { últimos } \\
12 \text { meses }\end{array}$} & $<100$ & 12 & 21,8 & 33 & 60,0 & 10 & 18,2 & 55 & \multirow{3}{*}{0,22} \\
\hline & 101 a 500 & 15 & 25,4 & 31 & 52,5 & 13 & 22,0 & 59 & \\
\hline & $>500$ & 2 & 6,1 & 23 & 69,7 & 8 & 24,2 & 33 & \\
\hline & Total & 29 & 19,7 & 87 & 59,2 & 31 & 21,1 & 147 & \\
\hline \multirow{4}{*}{$\begin{array}{l}\text { Margem líquida } \\
\text { de lucro }\end{array}$} & $<5 \%$ & 17 & 50,0 & 15 & 44,1 & 2 & 5,9 & 34 & \multirow{3}{*}{0,00} \\
\hline & $>5 \%=10 \%$ & 11 & 20,4 & 28 & 51,9 & 15 & 27,8 & 54 & \\
\hline & $>10 \%$ & 2 & 3,1 & 47 & 72,3 & 16 & 24,6 & 65 & \\
\hline & Total & 30 & 19,6 & 90 & 58,8 & 33 & 21,6 & 153 & \\
\hline \multirow{3}{*}{$\begin{array}{l}\text { Faturamento } \\
\text { bruto anual }\end{array}$} & $<=16$ milhões & 22 & 24,7 & 52 & 58,4 & 15 & 16,9 & 89 & \multirow{2}{*}{0,08} \\
\hline & $>16$ milhões & 8 & 12,5 & 38 & 59,4 & 18 & 28,1 & 64 & \\
\hline & Total & 30 & 19,6 & 90 & 58,8 & 33 & 21,6 & 153 & \\
\hline \multirow{3}{*}{$\begin{array}{l}\text { Tempo médio } \\
\text { dos produtos no } \\
\text { mercado }\end{array}$} & $<5$ anos & 19 & 19,4 & 61 & 62,2 & 18 & 18,4 & 98 & \multirow{2}{*}{0,00} \\
\hline & $>5$ anos & 11 & 20,0 & 29 & 52,7 & 15 & 27,3 & 55 & \\
\hline & Total & 30 & 19,6 & 90 & 58,8 & 33 & 21,6 & 153 & \\
\hline \multirow{4}{*}{$\begin{array}{l}\text { Lançamento de } \\
\text { novos produtos }\end{array}$} & $<=3$ & 18 & 34,0 & 24 & 45,3 & 11 & 20,8 & 53 & \multirow{3}{*}{0,08} \\
\hline & $>3$ a 10 & 5 & 11,4 & 26 & 59,1 & 13 & 29,5 & 44 & \\
\hline & $>10$ & 7 & 12,5 & 40 & 71,4 & 9 & 16,1 & 56 & \\
\hline & Total & 30 & 19,6 & 90 & 58,8 & 33 & 21,6 & 153 & \\
\hline \multirow{3}{*}{ Empresa exporta? } & Sim & 9 & 14,8 & 33 & 54,1 & 19 & 31,1 & 61 & 0,05 \\
\hline & Não & 21 & 22,8 & 57 & 62,0 & 14 & 15,2 & 92 & \\
\hline & Total & 30 & 19,6 & 90 & 58,8 & 33 & 21,6 & 153 & \\
\hline & Sim & 12 & 15,0 & 50 & 62,5 & 18 & 22,5 & 80 & 0,32 \\
\hline $\begin{array}{l}\text { Empresa im- } \\
\text { porta? }\end{array}$ & Não & 18 & 24,7 & 40 & 54,8 & 15 & 20,5 & 73 & \\
\hline & Total & 30 & 19,6 & 90 & 58,8 & 33 & 21,6 & 153 & \\
\hline
\end{tabular}

*Análise dos percentuais pelas linhas (100\%).

Fonte: Elaborada pelos autores. 
Por outro lado, o Cluster 2, mesmo sendo caracterizado em sua maioria por empresas do setor metalmecânico (39 companhias), concentra a maioria das que estão ligadas aos ramos eletroeletrônico $(81,8 \%)$ e automotivo $(66,7 \%)$. No geral, é formado por empresas com menos de 100 funcionários e que têm margens líquidas de lucro superiores a $10 \%$.

Outra característica nesse cluster é estar associado ao lançamento de novos produtos, uma vez que das 56 empresas que lançaram mais de dez produtos novos no mercado nos últimos dois anos, 40 encontram-se nesse agrupamento. Além disso, abrange o maior número de empresas exportadoras, ou seja, 33 dentre as 61 que praticam vendas no mercado externo.

É oportuno destacar que o Cluster 2 difere em níveis significativos do Cluster 1 quanto ao método de definição de Preços Baseado em Valor Percebido, por concordar mais com ele. Tal fato chama a atenção, pois $81,8 \%$ das empresas ligadas ao ramo eletrônico pertencem ao Cluster 2. Desse modo, buscou-se identificar o grau de concordância de tais empresas quanto ao método de definição de Preços Baseado em Valor Percebido. Analisando essa variável isoladamente nas companhias do ramo eletroeletrônico, foi constatado que 31 de um total de 33 que participaram da pesquisa possuem um grau de concordância acima de 5 quanto à prática desse método. Ademais, vale destacar que dez empresas (30,3\%) declararam concordar totalmente.

O Cluster 2 representa ter um desempenho superior quanto às margens líquidas de lucro declaradas em relação aos demais clusters. Isso sugere que uma Prática de Preços Altos aliada ao método de definição de Preços Baseado em Valor Percebido e um maior número de lançamentos de novos produtos tendem a trazer um desempenho superior.

Por fim, o Cluster 3 possui a maioria de empresas do ramo metalmecânico. No entanto, diferentemente do Cluster 1, esse grupo é formado em sua maioria por companhias maiores, acima de 100 funcionários, e por outros dois com margens líquidas de lucro superiores a $5 \%$ até $10 \%$ (15 empresas) e outro com aquelas com margens líquidas de lucro superiores a 10\% (16 empresas). O faturamento bruto anual das empresas desse grupo está distribuindo 
entre as duas categorias: 18 faturam acima de $R \$ 16$ milhões, e 15 possuem um faturamento menor que $\mathrm{R} \$ 16$ milhões.

Nessas empresas, o tempo médio dos produtos no mercado está distribuído muito similarmente: 18 estão com produtos há menos de cinco anos no mercado, e 15 com produtos acima desse tempo. Além disso, o número de lançamentos de produtos novos está distribuído similarmente, ou seja, 11 empresas lançaram menos de três produtos, 13 lançaram entre três e dez, e 9 lançaram acima de dez nos últimos dois anos. Por outro lado, esse cluster também reúne o maior número de empresas exportadoras.

Dessa maneira, o Cluster 3 é muito similar em desempenho ao Cluster 2, mas difere por concentrar um grupo de empresas maiores (acima de 100 funcionários) ligadas ao ramo metalomecânico: ou seja, das 33 desse grupo, 21 são do ramo metalmecânico e 18 empregam mais de 100 funcionários.

Assim, é possível observar com os dados apresentados nas Tabelas 5 e 6 que essas empresas tendem a ter um desempenho superior aos concorrentes, o que pode estar associado às empresas maiores que não dependem somente do mercado interno para comercializar seus produto. Isso se alia ao maior lançamento de novos produtos, apresentando um desempenho e atingimento de objetivos em nível superior ao demonstrado em relação aos demais clusters, o que pode estar associado, também, a produtos com maiores exigências destinados ao mercado externo e a nível de concorrência mais elevado.

Vale destacar, ainda, que o Cluster 3 é o que apresenta as maiores médias, combinando os três métodos de definição de preços 3 Cs (custos, concorrente e clientes valor percebido) a uma Estratégia de Preços Altos, diferenciando-o, assim, dos demais clusters identificados e analisados.

De acordo com o exposto no trabalho, o Quadro 3 tem o objetivo de contextualizar os aspectos relacionados às estratégias de precificação e níveis de desempenho dos clusters identificados. O Quadro 4, por sua vez, busca concentrar as características dos clusters identificados, com o intuito de sintetizar os dados desta seção. 
Quadro 3: Contextualização das estratégias de precificação e dos níveis de desempenho dos clusters identificados

\begin{tabular}{|c|c|c|}
\hline Cluster 1 & Cluster 2 & Cluster 3 \\
\hline $\begin{array}{l}\text { Preço Baseado em } \\
\text { Custos; } \\
\text { menor utilização de } \\
\text { Preço Baseado em } \\
\text { Valor Percebido }\end{array}$ & $\begin{array}{l}\text { Preço Baseado em } \\
\text { Custos; } \\
\text { definição de Preços } \\
\text { Baseado em Valor } \\
\text { Percebido }\end{array}$ & $\begin{array}{l}\text { Preço Baseado em Custos; } \\
\text { definição de Preços Basea- } \\
\text { do em Valor Percebido }\end{array}$ \\
\hline $\begin{array}{l}\text { Utiliza Estratégias de } \\
\text { Preços Baixos }\end{array}$ & $\begin{array}{l}\text { Empresas discordam } \\
\text { quanto à utilização } \\
\text { de Estratégias } \\
\text { de Preços Baixos; } \\
\text { Empresas utilizam } \\
\text { mais Estratégias de } \\
\text { Preços Altos }\end{array}$ & $\begin{array}{l}\text { Utilizam Estratégias } \\
\text { de Preços Altos }\end{array}$ \\
\hline $\begin{array}{l}\text { Desempenho inferior } \\
\text { ao seu principal con- } \\
\text { corrente }\end{array}$ & $\begin{array}{l}\text { Possui um desempe- } \\
\text { nho muito similar ao } \\
\text { seu principal concor- } \\
\text { rente }\end{array}$ & $\begin{array}{l}\text { Desempenho superior ao } \\
\text { seu principal concorrente }\end{array}$ \\
\hline $\begin{array}{l}\text { Atua em mercado } \\
\text { competitivo }\end{array}$ & $\begin{array}{l}\text { Desempenho do mer- } \\
\text { cado é visto com um } \\
\text { bom desempenho }\end{array}$ & $\begin{array}{l}\text { Percebe o mercado como } \\
\text { o melhor desempenho } \\
\text { dentre os demais clusters }\end{array}$ \\
\hline $\begin{array}{l}\text { Desempenho inferior } \\
\text { quanto ao lançamen- } \\
\text { to de novos produtos }\end{array}$ & $\begin{array}{l}\text { Melhor alcance dos } \\
\text { objetivos com o } \\
\text { lançamento de novos } \\
\text { produtos }\end{array}$ & $\begin{array}{l}\text { Apresenta o melhor } \\
\text { desempenho e o melhor } \\
\text { alcance dos objetivos } \\
\text { quanto ao lançamento de } \\
\text { novos produtos }\end{array}$ \\
\hline
\end{tabular}

Fonte: Elaborado pelos autores. 
Quadro 4: Caracterização dos clusters identificados

\begin{tabular}{|c|c|c|}
\hline Cluster 1 & Cluster 2 & Cluster 3 \\
\hline $\begin{array}{l}\text { Empresas ligadas } \\
\text { ao metalmecânico }\end{array}$ & $\begin{array}{l}\text { Empresas do metalo- } \\
\text { mecânico; } \\
\text { concentra a maioria das } \\
\text { empresas do eletroele- } \\
\text { trônico e automotivo }\end{array}$ & $\begin{array}{l}\text { Empresas ligadas } \\
\text { ao metalmecânico }\end{array}$ \\
\hline $\begin{array}{l}\text { Empresas com até } 19 \\
\text { funcionários }\end{array}$ & $\begin{array}{l}\text { Na maioria, empresas } \\
\text { com até } 100 \text { funcioná- } \\
\text { rios }\end{array}$ & $\begin{array}{l}\text { Maioria das empresas } \\
\text { com mais de } 100 \text { funcio- } \\
\text { nários }\end{array}$ \\
\hline $\begin{array}{l}\text { Empresas com menos } \\
\text { de } 500 \text { clientes ativos }\end{array}$ & $\begin{array}{l}\text { Não há diferenças entre } \\
\text { os números de clientes }\end{array}$ & $\begin{array}{l}\text { Não há diferenças entre } \\
\text { os números de clientes }\end{array}$ \\
\hline $\begin{array}{l}\text { Empresas com fatura- } \\
\text { mento } \\
\text { até } R \$ 16 \text { milhões }\end{array}$ & $\begin{array}{l}\text { Maioria das empresas } \\
\text { com faturamento acima } \\
\text { de } \mathrm{R} \$ 16 \text { milhões }\end{array}$ & $\begin{array}{l}\text { Maioria das empresas } \\
\text { com faturamento acima } \\
\text { de } \mathrm{R} \$ 16 \text { milhões }\end{array}$ \\
\hline $\begin{array}{l}\text { Margens líquidas de lu- } \\
\text { cro menores que } 10 \% \text { e } \\
\text { maioria com menos que } \\
5 \% \text { de margem líquida }\end{array}$ & $\begin{array}{l}\text { Concentra a maioria } \\
\text { das empresas com mar- } \\
\text { gens acima de } 20 \%\end{array}$ & $\begin{array}{l}\text { Dividido em empresas } \\
\text { com margens líquidas } \\
\text { acima de } 5 \% \text { e acima de } \\
10 \%\end{array}$ \\
\hline $\begin{array}{l}\text { Empresas lançaram me- } \\
\text { nos que três produtos } \\
\text { nos últimos dois anos }\end{array}$ & $\begin{array}{l}\text { Empresas lançaram } \\
\text { mais que dez produtos } \\
\text { nos últimos dois anos }\end{array}$ & $\begin{array}{l}\text { Não há diferença nos } \\
\text { números de lançamentos } \\
\text { de novos produtos }\end{array}$ \\
\hline $\begin{array}{l}\text { Menor número } \\
\text { de empresas exporta- } \\
\text { doras }\end{array}$ & $\begin{array}{l}\text { Maior número de } \\
\text { empresas exportadoras } \\
\text { dentre } \\
\text { os demais clusters }\end{array}$ & $\begin{array}{l}\text { Concentra a maioria } \\
\text { das empresas exportado- } \\
\text { ras }\end{array}$ \\
\hline $\begin{array}{l}\text { Formado por empre- } \\
\text { sas pequenas coma } \\
\text { margens de lucro } \\
\text { líquida inferior a } 5 \% \text {. } \\
\text { Atuando com Estraté- } \\
\text { gia de Preços Baixos } \\
\text { em ambiente competi- } \\
\text { tivo } \\
\text { Baixo Desempenho }\end{array}$ & $\begin{array}{l}\text { Concentra a maio- } \\
\text { ria das empresas do } \\
\text { eletroeletrônico e } \\
\text { automotivo. Utiliza } \\
\text { o Preço Baseado em } \\
\text { Valor Percebido obtém } \\
\text { as melhores margens } \\
\text { líquidas de lucro } \\
\text { Alto Desempenho }\end{array}$ & $\begin{array}{l}\text { Concentra a maioria } \\
\text { das empresas com mais } \\
\text { de } 100 \text { funcionários } \\
\text { e faturamento acima } \\
\text { de } 16 \text { milhões. Combina } \\
\text { os } 3 \text { Cs custos, concor- } \\
\text { rente e cliente juntamente } \\
\text { com preços altos } \\
\text { Alto Desempenho }\end{array}$ \\
\hline
\end{tabular}

Fonte: Elaborado pelos autores. 
Tais resultados atestam o que foi identificado por Indounas (2014) em relação à adoção de diferentes estratégias de preço em dois grupos de empresa. Em sua pesquisa, as companhias que adotaram estratégias de preços altos apresentaram desempenhos de mercado e financeiros melhores que aquelas com adoção de preços baixos. Quanto a esse estudo, os clusters 2 e 3 destacam-se positivamente quando comparados ao Cluster 1 . No entanto, mesmo com resultados semelhantes, os Clusters 2 e 3 possuem diferenças entre si, principalmente quanto à caracterização de cada um (Tabela 6 e Quadro 4).

\section{CONSIDERAÇões FINAIS}

Empresas que não gerenciam seus preços perdem o controle sobre eles, corroendo a sua lucratividade e a sua rentabilidade (SOON, 2011; HITERHUBER, 2004). Por outro lado, o preço é um processo como um feedback, no qual suposições precisam ser revistas e a dinâmica do ambiente ser levada em consideração, o que faz com o processo de precificação seja constantemente analisado dentro da empresa (HINTERHUBER, 2004).

Preços, por outro lado, podem ser praticados com arte e como ciência, pois podem envolver criatividade na definição do modelo a ser implementado ou investimentos em pesquisas para avaliar o nível ideal de preços a ser praticado (KOHLI; SURI, 2011). Nesse contexto, esta pesquisa buscou verificar a constituição de grupos de empresas a partir de suas estratégias de precificação e níveis de desempenho. Foram identificados três grupos (clusters), com diferenças em termos de métodos de precificação adotados e níveis de desempenho.

Primeiramente, ficou evidenciado que a estratégia de preços baixos está mais presente nas empresas que constituem o Cluster 1. Dessa forma, é possível observar que elas tendem a declarar maior dificuldade diante do seu desempenho em relação ao seu principal concorrente, atribuído a maior intensidade competitiva do mercado em que atuam.

Ao se analisarem as empresas quanto à adoção de estratégias de preços altos, constata-se que possuem melhores margens líquidas de lucro. No entanto, dizer só isso não é suficiente, pois dentre as que praticam a estratégia de preços altos, chama a atenção o 
fato de se concentrarem em dois grupos: o Cluster 3, já relatado anteriormente por caracterizar-se por empresas de maior porte do setor metalmecânico e que possuem um melhor desempenho, e, em especial, o Cluster 2.

No Cluster 3, o qual é formado, em sua maioria, por empresas maiores, tende a considerar como principal método de formação de preços aquele baseado em custos, seguido pelo método de formação de preços baseado em valor percebido. Esse grupo, com predomínio de margens líquidas de lucro superiores a $10 \%$, demonstrou possuir desempenho superior em relação aos seus principais concorrentes, ainda mais em relação aos seus custos e competitividade. Vale destacar que essas empresas lançam mais de três produtos novos a cada dois anos, ampliando a disponibilidade de ofertas e conseguindo se beneficiar com uma definição de preços baseada em valor percebido para seus produtos.

O Cluster 2, com predomínio dos preços baseados em custos e no valor percebido, concentrou a maioria das empresas dos ramos eletroeletrônico e automotivo, com número de funcionários inferior a 100. Chama a atenção também o seu desempenho, já que das 65 companhias que apresentam margens de contribuição superior a $10 \%, 47$ pertencem a esse grupo. Nesse sentido, pode-se concluir que há diferenças significativas entre os diferentes ramos de atividade.

Assim, de acordo com Hinterhuber (2004), as empresas podem variar seus objetivos de preços conforme o tipo de produto e/ou serviços, e ao longo do tempo, mesmo dentro de uma companhia ou unidade de negócios. Por outro lado, as estratégias de preços dependem do contexto em análise, o que pode fazer com que os gestores as modifiquem conforme as condições de mercado e o comportamento dos compradores e dos competidores. Assim, este estudo demonstrou que as empresas inseridas nesta pesquisa se encontram em diferentes contextos mercadológicos e necessitam utilizar diferentes estratégias, a depender da situação de mercado, da intensidade da concorrência e da própria situação da empresa (TORRES; MARTINS, 2006; NAGLE; HOGAN, 2007).

Por outro lado, os gestores precisam compreender o contexto de mercado no qual a empresa está inserida, considerando os aspectos externos e internos para a escolha da estratégia de precificação, o que 
inclui o método de definição de preços adequados aos seus produtos (MILAN et al., 2013; MONROE; COX, 2001) Além disso, necessitam compreender a relação do valor percebido pelos clientes e o grau de satisfação com os produtos (benefícios esperados versus sacrifícios incorridos) e transformá-los em informações que auxiliam a tomada de decisão dos preços. Para isso, a utilização de um sistema de informação estruturado e a elaboração de indicadores associados à precificação poderão contribuir para auxiliar a tomada decisão.

Como limitação da pesquisa, destaca-se que questionários autoadministrados podem não refletir o que os entrevistados realmente fazem quanto à gestão do processo de precificação. Outra limitação é que as medidas de desempenho (faturamento, lucro, rentabilidade) são utilizadas de acordo com a declaração dos próprios entrevistados em relação aos seus concorrentes.

Quanto ao desenvolvimento de futuros estudos, sugere-se investigar como as características organizacionais e comportamentais de clientes e/ou consumidores afetam as políticas, as decisões e as estratégias de preços em relação ao desempenho das empresas (LIOZU; HINTERHUBER, 2012); ou seja, a influência das características das empresas, de sua estrutura e dos gestores envolvidos nas decisões sobre as estratégias de precificação continua a ser importante para o desenvolvimento de novas pesquisas (NOBLE; GRUCA, 1999). Por outro lado, poderiam ser abordados mais estudos aprofundando as diferentes necessidades e fatores que levam as empresas a tomarem decisões diferentes de precificação em relação ao ramo de atividade e ao contexto de mercado em que estão inseridas.

\section{REFERÊNCIAS}

AVLONITIS, G.; INDOUNAS, A. Pricing objectives and pricing methods in the service sector. Journal of Services Marketing, Bingley, v. 19, n. 1, p. 47-57, 2005.

COELHO, F. S. Formação estratégica de precificação: como maximizar o resultado das empresas. São Paulo: Atlas, 2007.

CRESSMAN JR., G. E. Commentary on industrial pricing: theory and managerial practice. Marketing Science, Catonsville, v. 18, n. 3, p. 455-457, 1999.

. Value-based pricing: a state-of-the-art review. In: LILIEN, G.; GREWAL, R. (Ed.). Handbook on business to business marketing. Massachusetts: Edward Elgar Publishing, 2012. chapter 14, p. 246-269. 
DOLAN, R. J.; SIMON, H. O poder dos preços: as melhores estratégias para ter lucro. São Paulo: Futura, 1998.

ENDERS, C. K. Applied missing data analysis. New York: The Gilford Press, 2010.

FIELD, A. Discovering statistics using IBM SPSS statistics. Sage, 2013.

FINK, L. D. Creating significant learning experiences: an integrated approach to designing college courses. John Wiley \& Sons, 2013.

FOWLER JR., F. J. Survey research methods. $4^{\text {th }}$ edition. Thousand Oaks: Sage Publications, 2009.

FÜREDER, R.; MAIER, Y.; YARAMOVA, A. Value-based pricing in Austrian médium-sized companies. Strategic Management, Subotica, v. 19, n. 10, p. 13-19, 2014.

HAIR JR., J. F.; BLACK, W. C.; BABIN, B. J.; ANDERSON, R. E.; TATHAM, R. L. Análise multivariada de dados. 6. ed. Porto Alegre: Bookman, 2009.

HAWS, K. L.; BEARDEN, W. O.; NETEMEYER, R. G. (Ed.). Handbook of marketing scales: multi-item measures for marketing and consumer behavior research. Sage, 2011.

HINTERHUBER, A. Towards value-based pricing: an integrative framework for decision making. Industrial Marketing Management, Amsterdam, v. 33, n. 8, p. 765-778, 2004.

HINTERHUBER, A. Customer value-based pricing strategies: why companies resist. Journal of Business Strategy, Bingley, v. 29, n. 4, p. 41-50, 2008.

HINTERHUBER, A.; LIOZU, S. Is it time to rethink your pricing strategy? Sloan Management Review, Cambridge, MA, v. 53, n. 4, p. 69-77, 2012.

. Innovation in pricing: contemporary theories and best practices. New York: Routledge, 2013.

HOLLENSEN, S. Marketing management: a relationship approach. London: McGraw-Hill, 2006.

HOOLEY, G. J.; PIERCY, N. F.; NICOLAUD, B. Estratégia de marketing e posicionamento competitivo. 4. ed. São Paulo: Pearson, 2011.

INDOUNAS, K. The antecedents of strategic pricing and its effect on company performance in case of industrial service firms. Journal of Service Marketing, Bingley, v. 28, n. 5 p. 402-413, 2014.

INGENBLEEK, P.; DEBRUYNE, M.; FRAMBACK, R.; VERHALLEN, T. M. Successful new product pricing practices: a contingency approach. Marketing Letters, Basel, v. 14, n. 4, p. 289-305, 2003.

INGENBLEEK, P.; FRAMBACH, R. T.; VERHALLEN, T. Best practices for new product pricing: impact on market performance and price level under different conditions. Journal of Product Innovation Management, New Jersey, v. 30, n. 3, p. 560-573, 2013.

INGENBLEEK, P.; VAN DER LANS, I. A. Relating price strategies and price-setting practices. European Journal of Marketing, Bingley, v. 47, n. 1/2, p. 27-48, 2013. 
JAIN, S. Marketing planning and strategy. $7^{\text {th }}$ edition. Mason: Thomson Custom Publishing, 2004.

JOHNSON, R. A.; WICKERN, D. W. Applied multivariate statistical analysis. $6^{\text {th }}$ edition. Upper Saddle River: Pearson / Prentice Hall, 2007.

KLINE, R. B. Principles and practice of structural equation modeling. New York: Guilford Press, 2011.

KOHLI, C.; SURI, R. The price is right? Guidelines for pricing to enhance profitability. Business Horizons, Amsterdam, v. 54, n. 6, p. 563-573, 2011.

LAMB JR., C. W.; HAIR JR., J. F.; MCDANIEL, C. Princípios de marketing. São Paulo: Thomson Learning, 2004.

LANCIONI, R. A strategic approach to industrial product pricing: the pricing plan. Industrial Marketing Management, Amsterdam, v. 34, n. 2, p. 177-183, 2005.

LARENTIS, F.; GIACOMELLO, C. P.; CAMARGO, M. E. Análise da importância em pesquisas de satisfação através da regressão múltipla: estudo do efeito de diferentes pontos de escala. Análise - Revista de Administração da PUCRS, Porto Alegre, v. 23, n. 3, p. 258-269, 2012.

LARENTIS, F.; MILAN, G. S.; DE TONI, D.; GAVA, A. Formação e estratégias de preços: um estudo quantitativo-descritivo sobre a prática de empresas da Serra Gaúcha. Análise - Revista de Administração da PUCRS, Porto Alegre, v. 24, n. 1, p. 28-41, 2013.

LIOZU, S. M.; HINTERHUBER, A. Industrial product pricing: a value-based approach. Journal of Business Strategy, Bingley, v. 33, n. 4, p. 28-39, 2012.

Pricing orientation, pricing capabilities, and firm performance. Management Decision, Bingley, v. 51, n. 3, p. 594-614, 2013 a.

The confidence factor in pricing: driving firm performance. Journal of Business Strategy, Bingley, v. 34, n. 4, p. 11-21 2013b.

MALHOTRA, N. K. Pesquisa de marketing: uma orientação aplicada. 4. ed. Porto Alegre: Bookman, 2012.

MALHOTRA, N. K.; BIRKS, D. F.; WILLS, P. Marketing research: an applied approach. Harlow: Financial Times, 2012.

MILAN, G. S.; DE TONI, D.; LARENTIS, F.; GAVA, A. M. Relação entre estratégias de preços e custeio. RCA - Revista de Ciências da Administração, Florianópolis, v. 1, n. 1, p. 229-244, 2013.

MONROE, K. B. Pricing making profitable decisions. $3^{\text {rd }}$ edition. International Edition. New York: McGraw-Hill/Irwin, 2003.

MONROE, K. B.; COX, J. L. Pricing practices that endanger profits. Marketing Management, Chigaco, v. 10, n. 3, p. 42-46, 2001.

MULAIK, S. A. Foundations of factor analysis. $2^{\text {nd }}$ edition. Boca Raton: Taylor \& Francis Group, 2010.

NAGLE, T. T.; HOLDEN, R. K. Estratégias e táticas de preços. 3. ed. São Paulo: Prentice Hall, 2003. 
NAGLE, T. T.; HOGAN, J. E. Estratégia e táticas de preço: um guia para crescer com lucratividade. São Paulo: Pearson, 2007.

NICHELE, M.; MILAN, G. S. Fundamentos estratégicos e decisões de preço. In: MILAN, G. S.; BRANCHI, N. V. L. (Org.). Administração mercadológica: teoria e pesquisas. Volume 2. Caxias do Sul: EDUCS, 2006. Cap. 7, p. 151-180.

NOBLE, P. M.; GRUCA, T. S. Industrial pricing: theory and managerial practice. Marketing Science, Catonsville, v. 18, n. 3, p. 435-454, 1999.

RAO, V. R.; KARTONO, B. Pricing objectives and strategies: a cross-country survey. In: RAO, V. R.; KARTONO, B. (Ed.). Handbook of pricing research in marketing. Massachusetts: Edward Elgar Publishing, 2009. Chapter 1, p. 9-36.

REMLER, D. K.; VAN RYZIN, G. G. Research methods in practice: strategies for description and causation. Thousand Oaks: Sage Publications, 2011.

SAXENA, R. Marketing management. $4^{\text {th }}$ ed. New Delhi: Tata McGraw-Hill, 2009.

SEMENIK, R. J.; BAMOSSY, G. J. Princípios de marketing: uma perspectiva global. São Paulo: Makron Books, 1997.

SIMON, H.; BILSTEIN, F. F.; LUBY, F. Gerenciar para o lucro, não para a participação de mercado. Porto Alegre: Bookman, 2008.

SOON, W. A review of multi-product pricing models. Applied Mathematics and Computation, v. 217, n. 21, p. 8149-8165, 2011.

TELLIS, G. J. Beyond the many faces of price: an integration of pricing strategies. Journal of Marketing, Chicago, v. 50, n. 4, p. 146-60, 1986.

TORRES, U. P. P.; MARTINS, H. C. Análise estratégica das áreas de marketing e finanças no processo de formação e manutenção dos preços: o caso da montadora Fiat Automóveis S/A. In: EMA - ENCONTRO DE MARKETING DA ANPAD, 2., Rio de Janeiro. Anais eletrônicos... Rio de Janeiro: ANPAD, 2006.

URDAN, A. T. Práticas e resultados de apreçamento nas empresas brasileiras (1 $\mathbf{1}^{\mathbf{a}}$ parte). FGV Pesquisa, Relatório 10/2005. São Paulo: FGV/EASP, 2005.

VICINI, L.; SOUZA, A. M. Análise multivariada da teoria à prática. Santa Maria: UFSM, CCNE, 2005.

WEIJTERS, B; CABOOTER, E.; SCHILLEWAERT, N. The effect of rating scale format on response styles: the number of response categories and response category labels. International Journal of Research in Marketing, Amsterdam, v. 27, n. 3, p. 236-247, 2010. 


\section{APÊNDICE - Variáveis (ou questões) consideradas na pesquisa}

Processo de definição de preços: V01: As vantagens que o produto oferece ao cliente; V02: $\mathrm{O}$ equilíbrio entre as vantagens do produto e o possível preço; V03: As vantagens que o produto oferece em comparação aos produtos dos concorrentes; V04: O valor percebido do produto pelos clientes (benefícios versus custos); V05: O preço dos produtos dos concorrentes; V06: O grau de competição no mercado; V07: Os sistemas de vendas, divulgação e distribuição dos concorrentes; V08: A atual estratégia de preço dos concorrentes; V09: As reações dos concorrentes aos preços da nossa empresa; V10: As vantagens competitivas dos concorrentes no mercado; V11: O custo total do produto; V12: Os custos variáveis do produto; V13: A margem percentual de lucro definida pela empresa em relação ao preço do produto; V14: $\mathrm{O}$ volume de faturamento (receitas) necessário para que se atinja o ponto de equilíbrio; e V15: Os investimentos em um novo produto. Desempenho de novos produtos: V16: O produto ofereceu qualidade superior (maior) em relação aos concorrentes; V17: O produto solucionou problemas que os clientes tinham com produtos concorrentes; e V18: O produto foi bastante inovador e serviu como substituto a outros produtos existentes. Estratégias de precificação: V19: Definimos o preço inicialmente alto e então, sistematicamente, o reduzimos com o tempo ; V20: Nossos clientes esperam que o preço caia com o tempo; V21: Definimos o preço baixo para alavancar o volume de vendas e reduzir custos através da experiência acumulada; V22: Sempre procuramos ter um preço baixo (menor) no mercado em relação aos concorrentes; V23: Oferecemos produtos a um preço maior nos segmentos de mercado mais importantes e a um preço menor, por meio de descontos, em segmentos de mercado menos importantes; V24: Oferecemos descontos de forma sistemática e previsível; V25: Nossos clientes observam os preços de nossos produtos como indicadores de alta qualidade; V26: Para produtos que possuem itens complementares ou opcionais (tais como acessórios, partes, peças e serviços), colocamos uma margem de lucro menor no produto básico (central) e margens de lucros maiores nos itens complementares (preço premium); V27: Nossos preços estão em nível intermediário no mercado em função da qualidade intermediária de nossos produtos, em relação aos concor- 
rentes; V28: Oferecemos produtos a preços competitivos, mas também em uma versão mais simples, com menos características ou opções, se comparadas às outras versões; V29: Nossos preços são baixos no mercado em função da qualidade inferior de nossos produtos, em relação à concorrência; e V30: Oferecemos pacotes de produtos (um conjunto de vários produtos) em um preço total que permitem aos clientes boas economias se considerassem os produtos comprados individualmente (separadamente). Objetivos dos novos produtos: V31: Objetivos de vendas desde que foi lançado; V32: Objetivos de participação de mercado desde o lançamento; e V33: Margens de lucro esperadas desde o lançamento. Desempenho em comparação aos principais concorrentes: V34: Vantagem de custos devido à curva de experiência; V35: Vantagem de custos devido às economias de escala; V36: Participação de mercado (7 indica o líder de mercado); V37: Diferenciação dos produtos, de forma geral; V38: Custos totais; V39: Custos fixos; V40: Número de clientes ativos (considerando últimos 12 meses); V41: Preços dos produtos, de forma geral; V42: Crescimento médio no volume das vendas; V43: Capacidade em detectar mudanças de preços; V44: Margem de contribuição média (receitas menos custos variáveis) na venda dos produtos básicos (ou dos produtos "comercializados", para empresas que não trabalhem também com produtos e/ou serviços complementares); V45: Margem de contribuição média (receitas menos custos variáveis) na venda dos produtos (acessórios, opcionais) e/ou serviços complementares, caso existam; V46: Número de itens de produtos comercializados (em linha); V47: Número médio de anos no mercado dos principais produtos comercializados; e V48: Número de lançamentos de novos produtos (considerar últimos dois anos). Desempenho do principal mercado de atuação: V49: Crescimento do mercado como um todo; V50: Competição de preços; V51: Sensibilidade dos clientes às diferenças de preço entre marcas (concorrentes); V52: Sensibilidade da demanda total às mudanças no preço médio; V53: Qualidade dos produtos como um todo (no mercado, empresa e concorrentes); V54: Custos totais do setor como um todo; V55: Custos fixos do setor como um todo; V56: Margem de contribuição (receitas menos custos variáveis) na venda dos produtos do setor como um todo; V57: Rentabilidade média do setor como um todo; V58: Barreiras de entrada no mercado aos novos entrantes (con- 
correntes potenciais); V59: Poder de barganha dos clientes no setor como um todo; V60: Poder de barganha dos fornecedores no setor como um todo; e V61: Número de itens de produtos comercializados (em linha) no setor como um todo. Escalas utilizadas: V01 a V15: 1. Totalmente desconsiderado a 7. Totalmente considerado; V16 a V30: 1. Discordo totalmente a 7. Concordo totalmente; V31 a V33: 1. Nada alcançado a 7. Totalmente alcançado; V34 a V48: 1. Baixo desempenho a 7. Alto desempenho; e V49 a V61: 1. Baixo(a) a 7. Alto(a).

Recebido em: 4-1-2017

Aprovado em: 24-4-2017

Avaliado pelo sistema double blind review.

Editor: Elmo Tambosi Filho

Disponível em http://mjs.metodista.br/index.php/roc 